\title{
POLLEN SENSITIVENESS IN CHILDREN WITH ASTHMA
}

BY

R. BRUCE PEARSON, D.M., M.R.C.P.*

(From the Hospital for Sick Children, Great Ormond Street, and Guy's Hospital.)

Grass pollen is well recognized as a common cause of symptoms of allergic hypersensitivity. The frequency with which pollen sensitiveness is manifested by hay fever tends to divert attention from its importance as a factor in the causation of asthmatic attacks, except in those patients in whom hay-fever is present in addition to their asthma, or the small group who have attacks of asthma in the pollen season only. It was with the idea of attempting to find out the frequency with which pollen sensitization occurred in asthmatic children in this country that the following investigation was carried out. We have failed to trace any references in the literature which throw light on this subject.

The work was suggested by the fact that a considerable number of patients who had been having few or no attacks during the winter and early spring, apparently relapsed during May and June. Examination of the case notes of those who had been attending hospital for some time showed that this was an annual occurrence, and that whereas the attacks occurred occasionally during the winter months, a series of attacks were recorded in the early summer. Often this increase in the frequency of attacks was continued throughout the summer and only diminished in the autumn. Two hundred and fifty unselected cases attending the Asthma Clinic at the Hospital for Sick Children, Great Ormond Street, were investigated. Intradermal tests were carried out on two hundred and ten of these with a mixed pollen extract and a control solution of buffered phosphate. In addition, one hundred and forty-one were tested with a dust extract.

\section{Preparation of extracts.}

The pollen extract used was obtained by mixing the extracts of six pollens and diluting this mixture appropriately.

* Working for the Asthma Research Council with the aid of a grant from the Sir Hally Stewart Trust. 
The grasses used were Timothy, Orchard, Sheep's Fescue, Meadow, Vernal, 'Yorkshire Fog.'* This mixture contained 2 mgm. of nitrogen per cent. Two dust extracts were employed. These were made by extracting dust samples obtained from the houses of asthmatic individuals who appeared to be dust-sensitive clinically. The extracting fluid used was in one case Evans' Solution, and in the other an equal quantity of buffered phosphate and glycerine. The extract obtained was passed through a Berkfeld filter and diluted ten times with Evan's Solution before use. The nitrogen contents of the two extracts were 7 and $20 \mathrm{mgm}$. per cent. respectively.

\section{Criterion of positive reaction.}

A reaction was called positive if an area of erythema with or without a wheal developed after ten minutes at the site of the injection, in the presence of a negative control. In the event of the control solution giving a reaction, as happened not infrequently among the group of cases in which eczema was or had been present, the reaction to the protein extract was only counted positive if it was definitely larger and more intense than the control.

The reaction when positive usually showed an increase in the size of the wheal by about $2-3 \mathrm{~mm}$. and the flare produced measured on the average 30-40 $\mathrm{mm}$. The same extract tested on cases of frank hay fever gave reactions of about the same size, but tending to be slightly larger. This method of testing is slightly more sensitive than the scratch method. The concentration of the pollen extracts used for the scratch test was approximately sixteen times as strong as that of each individual pollen in the mixed solution for intradermal use. Twenty cases were compared by testing with the scratch and the intradermal method with the following results:-

\begin{tabular}{|c|c|c|c|c|}
\hline & \multicolumn{2}{|c|}{ SCRatch MethoD } & \multicolumn{2}{|c|}{ INTRADERMAL } \\
\hline & Positive & Negative & Positive & Negative: \\
\hline Twenty cases & 8 & 12 & 11 & 9 \\
\hline
\end{tabular}

\section{Results of investigation.}

The 250 patients examined were subdivided into four clinical groups :-

1. Those whose asthma occurred at all seasons of the year with no special seasonal incidence.

2. Those who were worse in the summer.

3. Those who were worse in the winter.

4. Those whose symptoms had not been present for a sufficient length of time to allow classification into the above groups.

The relative proportions of these groups and their reactions to pollen and dust are shown in the following table.

* Obtained from Messrs. Duncan \& Flockhart, 


\begin{tabular}{|c|c|c|c|c|c|}
\hline & $\begin{array}{c}\text { Relative } \\
\text { PROPORtion. } \\
\text { Percentage } \\
\text { OF total }\end{array}$ & $\begin{array}{c}\text { Percentage } \\
\text { Sensitive to } \\
\text { POLLeN }\end{array}$ & $\begin{array}{c}\text { Number } \\
\text { TESTED }\end{array}$ & $\begin{array}{c}\text { Percentage } \\
\text { SENSItIVe to } \\
\text { HOUSE DUSt }\end{array}$ & $\begin{array}{c}\text { Number } \\
\text { TESTED }\end{array}$ \\
\hline $\begin{array}{l}\text { Non-seasonal } \\
\text { asthmatics } \\
\text { Asthmatics } \\
\text { worse in } \\
\text { summer } \\
\text { Asthmatics } \\
\text { worse in } \\
\text { winter } \\
\text { Asthmatics } \\
\text { of recent } \\
\text { origin }\end{array}$ & $\begin{array}{l}\quad 1 \\
33 \\
\\
28\end{array}$ & $\begin{array}{l}33 \\
61\end{array}$ & 66 & 85 & 47 \\
\hline
\end{tabular}

From these figures there can be no doubt that grass pollen is an allergen of greater importance in the precipitation of asthmatic attacks than is generally recognized. If the total number of patients tested is taken, 42 per cent. give skin reactions to pollen. A series of thirty-three children of the same age group, not suffering from any allergic condition, attending general medical out-patients, were tested with the same extract: none of them gave any reaction.

If the asthmatic groups are subdivided according to age an increase in the number of cases giving positive reactions occurs after the age of nine years.

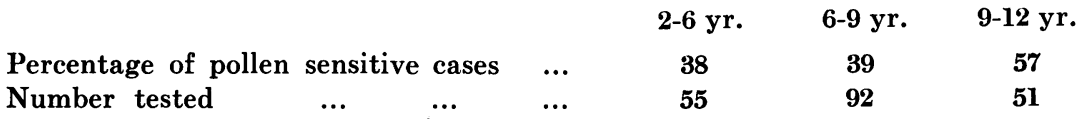

This is in accordance with the well-recognized fact that sensitiveness to inhalants becomes more marked as childhood advances.

When sensitiveness to pollen was considered in relation to the mode of onset, the following figures were obetained:-

MODE OF ONSET IN 250 PATIENTS

$\begin{array}{llr}\text { After eczema (20 per cent.) } \ldots & \ldots & 66 \\ \text { Spontaneous asthma }(22 \text { per cent.) } & \ldots & 42 \\ \text { After bronchitis and other respiratory } & \\ \text { infections (44 per cent.) } \ldots & \ldots & 34 \\ \text { After hay-fever (1 per cent.) } & \ldots & 100 \\ \text { Miscellaneous (13 per cent.) } & \ldots & 10\end{array}$

Thus the group who have or have had allergic eczema (20 per cent. of the series), show the highest proportion of reactors (66 per cent.). The capacity for sensitization to allergens of all types seems to be far higher in this than in any other group. For example, 42 per cent. claimed to be clinically sensitive to certain foods compared with 12 per cent. of the remainder: 22 per cent. were clinically egg-sensitive compared with 4 per cent. of the rest. 
The group of apparently pure spasmodic asthma gives the next figure of 42 per cent., while those patients in whom asthma followed a respiratory infection (such as bronchitis, whooping cough, pneumonia), give 34 per cent. positive responses.

\section{Discussion.}

The seasonal variations in the frequency of attacks among asthmatics depend on a number of unrelated factors. A large proportion of children suffering from asthma are regularly found to be worse during the summer months. There are at least three factors which may be responsible for this increase in severity.

First, the actual increase in the temperature of the air appears in certain cases to favour the allergic state, possibly by disturbing the balance of sympathetic and parasympathetic tone. This factor is of particular importance in children whose vasomotor instability is well recognized. Secondly, the presence of grass pollen in the air during the summer* means that in addition to the ordinary constituents of dust, a further potent allergen is inhaled in relatively large amounts. Owing to the drier weather, the total quantity of dust in the atmosphere will also be increased. Thirdly, in the case of children there is far less restriction on their movements and activities in the fine warm weather. They are allowed to wander further afield, and owing to the extended daylight the hour at which they go to bed is delayed. This means that in many cases children of poor stamina become unduly fatigued during the summer months. Fatigue or any other factor tending to lower the general health predisposes to asthmatic attacks. It must also be remembered that naso-pharyngeal and respiratory infections are not uncommonly acquired as a result of a chill following violent exercise.

The series of tests carried out in this paper indicates that grass pollen sensitization is of greater importance than is usually recognized. Whereas 5.6 per cent. of the patients tested, claimed to have clinical hay-fever in addition to their asthma, 42 per cent. reacted to a mixed pollen extract in weak dilution. In a certain number of these it was recognized that going into fields, or 'being in the garden when the grass is mown' brought on attacks. Many were unaware that contact with pollen was in any way responsible for attacks. This lack of clinical confirmation is so common in cases of inhalant sensitiveness as to be almost usual: very few feathersensitive patients realise that contact with feathers is responsible for their nocturnal asthma, though quite a high proportion are improved by discarding their feather-filled bedding material.

* It is not sufficiently recognized that though the majority of grasses pollinate during the latter half of May, all June and half of July, there are several (e.g., Timothy, Creeping Bent, Dog's Tooth) that pollinate in August and September, and many hay-fever sufferers have a second period during which their symptoms recur during August and early September. 
The previous failure to observe that face powder causes symptoms in cases of spasmodic rhinorrhoea among women, who are relieved at once by its omission, is a constant source of surprise. The absence of clinical confirmation of pollen sensitivity need not therefore lead us to deny its presence. Its clinical recognition is largely a question of education. Food sensitiveness is, on the other hand, in our experience far more frequently recognized by the patient.

An attempt to obtain some sort of clinical confirmation was obtained by subdividing the patients who were worse in the summer from the remainder; and it was shown that whereas 61 per cent. of the former were pollen sensitive only 33 per cent. of the latter gave positive skin reactions. It must be recognized that this is only a rough method of subdividing these patients, based entirely on the statement of the parents. Several of the patients said to be worse in the winter admitted to having more or less constant wheezing in June and July.

Two preparations of dust extract were used on many of the patients in this series, and the results obtained were in some ways surprising. The dust used was obtained from the sweepings of rooms of asthmatics: it was thought that since more time is spent by the children indoors in the winter than the summer that the percentage giving positive reactions would at least be roughly equal in the two groups. As the figures show, however, the summer group give a higher proportion of reactors ( 85 per cent.) than the winter group (56 per cent.), the group showing no seasonal incidence occupying a middle position (68 per cent.). This would not be surprising if the dust had been obtained from some outdoor source, in which the proportion of vegetable debris might be presumed to be greater than in house dust and present in the air in increased amounts during the summer months. As it is one is left to conclude that the summer group as a whole have a greater tendency to develop sensitization than the winter group in whom respiratory infections play a more prominent part. Moreover, it suggests that though infection of the respiratory tract may and almost certainly does predispose to development of protein sensitization, it is also responsible for development of the symptoms of asthma by other means-possibly due to reflex spasm. Further confirmation of the increased sensitivity of the summer group is found in the figures for sensitiveness to foods-32 per cent. of those worse in the summer claiming to be unable to eat certain forms of food compared with 24 per cent. of the other two groups. ${ }^{*}$ It may be mentioned that this increased tendency to develop hypersensitivity is not due to the presence of a greater proportion of eczema cases in its composition, the figures for the 'summer,' ' winter' and ' non-seasonal' groups being 17, 18 and 22 per cent. respectively.

Enumeration of unusual causes of sensitization responsible for allergic symptoms is of scientific interest, but at the same time is of small value

* No effort was made to confirm this sensitivity to foods which was based purely on the mothers' observations. 
in dealing with the average case of asthma. The frequency with which grass pollen acts as an allergen in asthma cases, however, apart from those with definite hay-fever, affords information of value in treatment of the condition. The figure of 42 per cent. for pollen sensitive cases compares with 60 per cent. for a series of the same age group tested with chicken feather extract in a comparable dilution ( $2 \mathrm{mgm}$. nitrogen per cent.). Pollen therefore may be placed with chicken feathers and horse hair as being one of the antigens to which exposure is almost universal, and to which a very high proportion of asthmatics are sensitive.

Just as the routine removal of feathers and hair containing materials from the environment of asthmatics is often accompanied by a very definite improvement in the frequency of attacks, so may avoidance of contact with pollen be of value. This is possible at all events as far as more intimate contact is concerned. Thus ' a day in the country' is often followed by an attack which might not occur after ' a day at the sea.' Many parents who have moved from the town to the country for the benefit of the child's health, might have been warned that increased contact with pollen would probably be followed by an increase in the number of attacks during the summer months, and so be saved from disappointment. Pollen-sensitive cases are not uncommonly free from their symptoms if they go to the seaside during the pollen season, provided they choose a place where the prevailing wind comes off the sea. Such patients would be well advised to take their summer holidays in June or early July. Finally, in cases where the offending allergen is recognized, improvement and not uncommonly relief, at least temporary, does follow injection of increasing amounts of the substance in question. The fact that so few cases are sensitive to one allergen only, is apt to obscure this fact. The treatment of hay-fever with pollen extracts is on the whole successful. Treatment of pollen-sensitive asthmatics by injection of pollen extract with or without extracts of other common allergens is therefore a reasonable procedure which is likely to be followed by a decrease in the frequency and severity of attacks.

My thanks are due to the physicians to out-patients at the Hospital for Sick Children, Great Ormond Street, for allowing me to make use of their cases.

\section{Conclusions.}

1. Of two hundred and fifty children 42 per cent. gave positive intradermal reactions to grass pollen extract.

2. Of those whose symptoms were more intense during the summer months 61 per cent. are sensitive compared with 32 per cent. of the remainder.

3. Those cases who have or have had eczema give a higher proportion of reactors than any other group, except the occasional case whose asthma has developed after and apparently as a direct result of hay-fever.

4. Suggestions are made with regard to treatment. 